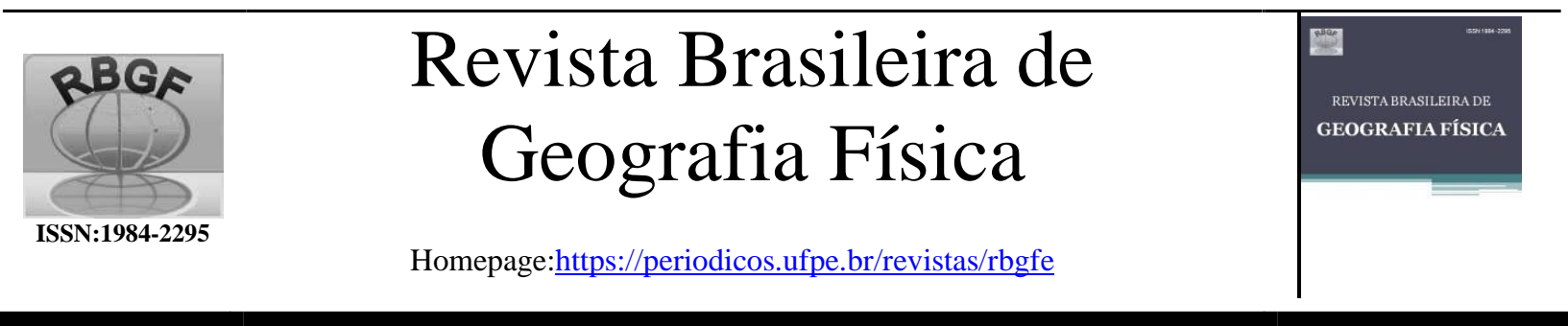

\title{
Passifloraceae s.s. na Chapada do Araripe, nordeste do Brasil
}

\author{
Francisca Graciele Leite Sampaio de Souza ${ }^{1}$, Maria Arlene Pessoa da Silva ${ }^{2}$, Maria Iracema Bezerra Loiola ${ }^{2,3}$
}

${ }^{1}$ Parte da dissertação desenvolvida no Programa de Pós-graduação em Bioprospecção Molecular da Universidade Regional do Cariri, Campus do Pimenta, CEP 63100-000, Crato, CE, Brasil. E-mail: graciele-1996@hotmail.com - autor correspondente.

${ }^{2}$ Doutora, Professora do Programa de Pós-graduação em Bioprospecção Molecular da Universidade Regional do Cariri, Campus do Pimenta, CEP 63100-000, Crato, CE, Brasil. E-mail: arlene.pessoa@urca.br

${ }^{3}$ Doutora, Professora Titular do Departamento de Biologia da Universidade Federal do Ceará, Campus do Pici Prof. Prisco Bezerra, CEP 60440-900, Fortaleza, CE, Brasil. E-mail: iloiola@ufc.br

Artigo recebido em 22/10/2020 e aceito em 24/03/2020-19/04/2021

\section{R E S U M O}

A Chapada do Araripe, localizada entre os estados do Ceará, Pernambuco e Piauí, abrange diferentes fitofisionomias e é reconhecida pela alta diversidade biológica e endemismos. O objetivo com este levantamento florístico foi identificar as espécies de Passifloraceae s.s. ocorrentes na Chapada do Araripe, bem como conhecer a distribuição geográfica associada aos habitats preferenciais e a fenologia, visando conhecer melhor a flora local. Foram realizadas coletas em campo no período de fevereiro a junho/2020 em vários municípios e a coleção resultante foi depositada no Herbário Caririense Dárdano de Andrade-Lima- HCDAL. As identificações das espécies foram baseadas na análise de características morfológicas das amostras em campo e de exsicatas dos herbários CEN, EAC, HCDAL, HST, IPA, MBM, PEUFR e UFP, complementadas com o auxílio de bibliografias especializadas. Na Chapada do Araripe foram registrados nove táxons de Passiflora, ocorrendo preferencialmente em Floresta Ombrófila Densa (Mata Úmida), mas também há registros na Floresta Estacional Semidecidual (Mata Seca), Savana (Cerrado), Savana Florestada (Cerradão), Savana Estépica (Caatinga/Carrasco), Savana Estépica Arborizada (Caatinga Arbórea). Passifloraceae s.s. está bem representada na Chapada do Araripe, são indicadas coletas inéditas para alguns munícipios, além disso, é necessário um maior esforço para coletar no estado do Piauí.

Palavras-chave: Diversidade, flora, região Neotropical, vegetação.

\section{Passifloraceae s.s. in the Chapada do Araripe, Northeast Brazil}

\begin{abstract}
A B S T R A C T
The Chapada do Araripe is located between the states Ceará, Pernambuco and Piauí, covers different phytophysiognomies and recognized by high biological diversity and endemisms. The aimed with this floristic survey was to identify species of the Passifloraceae s.s. to the Chapada do Araripe, as well as know geographic distribution associated with preferred habitats and phenology, aiming to know better local flora. Field collections were performed from February to June/2020 in several municipalities and the resulting collection is deposited at the Herbário Caririense Dárdano de Andrade Lima-HCDAL. The identifications of the species was based on the analysis of morphological characteristics of samples collected in the field and exsiccates from herbariums CEN, EAC, HCDAL, HST, IPA, MBM, PEUFR and UFP, complementered with assistance of specialized bibliographies. In the Chapada do Araripe nine taxa of Passifora were recorded, preferably occurring in the Dense Ombrophylous Forest (Mata Úmida), but also there are records in the Seasonal Semideciduous Forest (Mata Seca), Savanna (Cerrado), Florested Savanna (Cerradão), Stepic Savanna (Caatinga/Carrasco), Arboreus Stepic Savanna (Caatinga Arbórea) and transition zone of Savanna/ Seasonal Semideciduous Forest. Passifloraceae s.s. is well represented in the Chapada do Araripe, are indicated unpublished collections for some municipalities, in addiction is necessary greater effort to collect in Piaui State.

Keywords: Diversity, flora, Neotropical region, vegetation.
\end{abstract}

\section{Introdução}

A Chapada do Araripe está inserida no domínio da Caatinga, abrangendo parte dos estados do Ceará, Pernambuco e Piauí, região
Nordeste do Brasil. É considerada um dos relevos mais importante da região (Tavares Filho et al., 2020). Os solos e as condições geoambientais são 
bem diferenciados e os níveis altimétricos podem variar entre 700 e $1.000 \mathrm{~m}$, além da precipitação média anual que são superiores a áreas tipicamente sertanejas (Ferreira et al., 2016; Alcântara et al., 2020, Guerra et al., 2020), resultando em uma grande variedade de fitofisionomias.

Devido a estas peculiaridades, dois ambientes distintos são evidentes. Na zona úmida observa-se dois tipos de formas de relevo, o plano no topo da Chapada (de origem sedimentar e tabular) e o relevo ondulado nas encostas; já na zona semiárida, de relevo predominantemente aplainado, ocorrem níveis variados de semiaridez (Novaes e Laurindo, 2014; Queiroz et al., 2018; Simões Neto et al., 2018).

Embora estes ambientes sejam muito interessantes principalmente do ponto de vista vegetacional, taxonômico e ecológico, o conhecimento sobre a composição florística dos diversos tipos de vegetação que ocorrem sobre as serras e chapadas úmidas do semiárido brasileiro ainda é incipiente (Loiola et al., 2015). Na região Nordeste, os estudos dessas áreas úmidas encravadas no semiárido se concentram principalmente nos estados de Pernambuco (Pereira et al., 1993; Sales et al., 1998; Rodal et al., 2005); Paraíba (Agra et al., 2004) e Ceará (Costa et al., 2004; Alencar et al., 2007; RibeiroSilva, 2012; Loiola et al., 2015; Silveira et al., 2020a, b).

A Chapada do Araripe é uma dessas áreas classificadas como região de extrema importância, por abrigar testemunhos de antigas faunas $\mathrm{e}$ floras, de inestimável valor científico e reconhecida mundialmente por seu diversificado conteúdo fossilífero e preservação excepcional (Santos et al., 2020). Além de ter reconhecida relevância ambiental ecológica, possui também áreas onde são realizadas atividades educativas e turísticas (Moura-Fé, 2016).

Essa região é conhecida ainda por incluir espécies raras, endêmicas e até mesmo novas espécies para a ciência (Ferreira-Silva et al., 2019), além de abranger a Área de Proteção Ambiental da Chapada do Araripe, a Floresta Nacional do Araripe-Apodi e o Parque Geológico do Araripe (Tofeti e Campos, 2019).

No entanto, a área da Chapada do Araripe vem sofrendo uma intensa pressão antrópica devido principalmente ao crescente processo de ocupação humana desordenada, expansão agrícola e caça dos animais silvestres (Novaes et al., 2013). Essas perdas significativas dos recursos naturais são decorrentes principalmente do atual modelo de desenvolvimento socioeconômico e de políticas governamentais (Pereira et al., 2020).

Embora tenham sido realizados dois levantamentos florísticos na Chapada do Araripe (Ribeiro-Silva et al., 2012; Loiola et al., 2015), estes não revelaram a real diversidade de algumas famílias botânicas, como é o caso de Passifloraceae. No Brasil, Passifloraceae s.s. está representada por quatro gêneros (Ancistrothyrsus Harms, Mitostemma Mast., Dilkea Mast., Passiflora L.) e 161 espécies, das quais 89 são endêmicas (Flora do Brasil 2020 em construção). A família é composta por trepadeiras herbáceas ou lenhosas, com gavinhas, lâminas foliares inteiras ou lobadas (Costa et al., 2015, (Milward-deAzevedo, 2018).). Os representantes possuem características medicinais e ornamentais, mas é principalmente utilizado na alimentação humana (Bezerra et al., 2016).

Considerando a forma de crescimento (trepadeira) dos representantes do gênero Passiflora, a hipótese deste estudo é que as espécies tem uma grande amplitude ecológica, mas ocorrem preferencialmente em ambientes mais úmidos. $\mathrm{O}$ presente levantamento foi realizado com o objetivo de identificar as espécies da família Passifloraceae s.s. presentes na Chapada do Araripe, bem como conhecer a distribuição geográfica, os habitats preferenciais e a fenologia.

\section{Material e métodos}

Área de estudo

A área da Chapada do Araripe (Figura 1, Figura 2) compreende aproximadamente $180 \mathrm{~km}$ de extensão por $30-50 \mathrm{~km}$ de largura e abrange parte dos estados do Ceará, Pernambuco e Piauí (Figura 3), estando a maior parte no primeiro (Silva et al., 2012; Loiola et al., 2015; Ferreira et al., 2016; Alcântara et al., 2020).

O clima predominante na área é o Tropical úmido, com uma estação chuvosa de dezembro a maio; precipitação média anual variando de $700-1000 \mathrm{~mm}$; temperaturas entre $23^{\circ}$ e $27^{\circ} \mathrm{C}$, podendo registrar até $21^{\circ} \mathrm{C}$ entre os meses de maio a agosto (Ferreira et al., 2016). Os solos mais comuns são do tipo latossolos vermelhoamarelo e vermelho-escuro com boa profundidade, textura média e argilosa, bem drenados a acentuadamente drenados, muito lixiviados e intemperizados em toda sua profundidade (Macêdo et al., 2015). Nas encostas úmidas da Chapada do Araripe encontram-se diversas nascentes fluviais associadas com a 


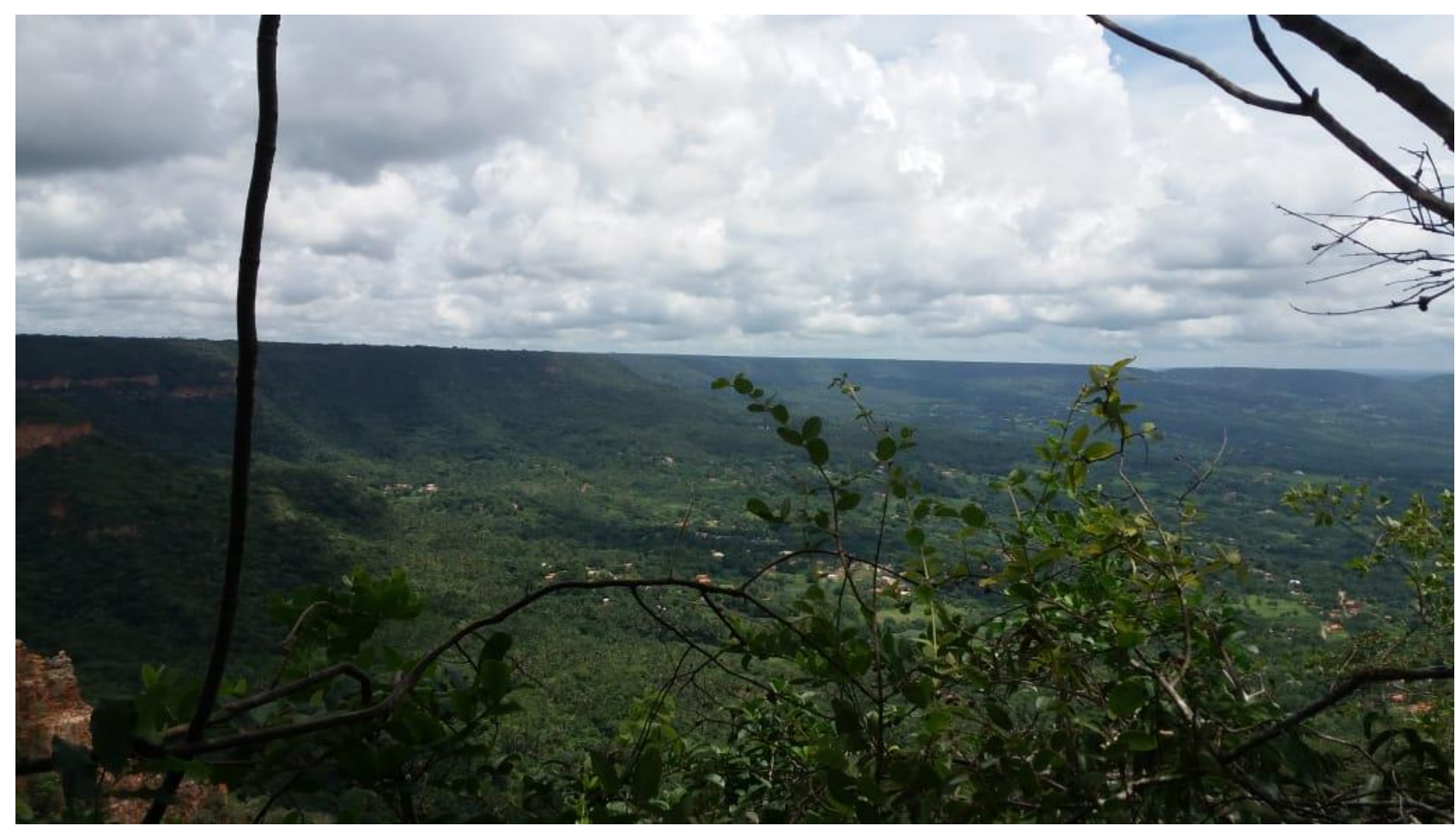

Figura 1- Vista do topo da Chapada do Araripe, na Trilha do Belmonte, Crato, CE - Floresta Ombrófila Densa (Mata Úmida).

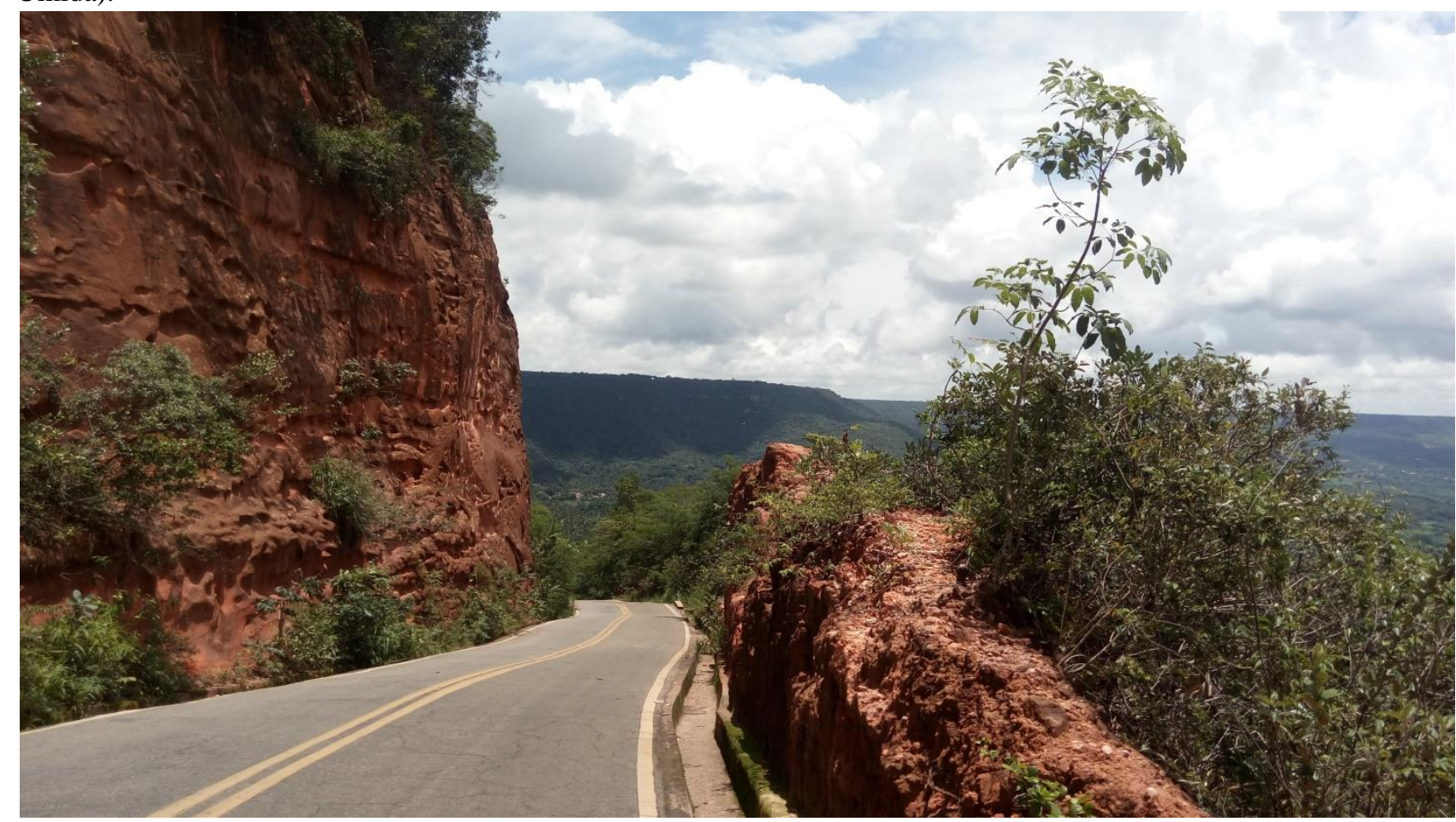

Figura 2- Vista da descida do Barreiro Grande em direção à zona urbana de Crato, CE - Savana Florestada (Cerradão).

ressurgência da água infiltrada no topo do relevo (Bastos et al., 2016).

Atualmente ainda se discute acerca dos limites municipais que fazem parte da Chapada. Nesse estudo foi considerada a listagem do ICMBio (2020), que estima 38 municípios.

\section{Levantamento Florístico}

As coletas em campo foram realizadas no período de fevereiro/2020 a junho/2020 em municípios previamente selecionados, seguindo o Manual Técnico da Vegetação Brasileira (IBGE, 2012). Toda a coleção foi depositada no Herbário 
Caririense Dárdano de Andrade-Lima (HCDAL). As identificações foram baseadas na observação dos caracteres morfológicos, com o auxílio de estereomicroscópio.

Os caracteres foram comparados com bibliografias especializadas (Costa et al., 2015; Borges e Milward-de-Azevedo, 2017; Imig et al., 2018), coleções dos herbários CEN, EAC, HCDAL, HST, IPA, MBM, PEUFR, UFP, cujas siglas estão de acordo com Thiers (continuamente atualizado) e do Herbário Sérgio Tavares - HST (não indexado). Os nomes dos táxons seguiram IPNI (2020).

As espécies foram fotografadas em câmera Nikon D7000 e celular LG K10 LTE. O nome popular, tipo de vegetação em que a espécie foi encontrada e dados sobre a fenologia foram observados em campo e nas etiquetas das exsicatas.

A morfologia baseou-se em Gonçalves e Lorenzi (2011). O mapa de distribuição geográfica das espécies foi elaborado utilizandose o Software Qgis versão 3.6, considerando uma espécie por município. Os tipos de vegetação em que as espécies ocorrem se basearam em Figueiredo (1997) e Manual Técnico da Vegetação Brasileira (IBGE, 2012).

\section{Resultados e Discussão}

$\mathrm{Na}$ Chapada do Araripe a família Passifloraceae está representada apenas pelo gênero Passiflora, onde foram registrados nove táxons: $P$. capsularis L., $P$. cincinnata Mast., $P$. edulis Sims, $P$. foetida $\mathrm{L}$. var. foetida, $P$. laurifolia L, P. picturata Ker Gawl., P. silvestris Vell., P. suberosa subsp. litoralis (Kunth) Port.Utl. ex M.A.M. Azevedo e P. tricuspis Mast.

No levantamento florístico desenvolvido por Loiola et al. (2015) foram indicadas seis espécies de Passiflora, entretanto, $P$. mucronata Lam. corresponde na realidade a $P$. silvestris e $P$. galbana Mast. é sinônimo de $P$. silvestris. No banco de dados Reflora (2020) estão registradas as espécies supracitadas e ainda $P$. coccinea Aubl. que corresponde à $P$. cincinnata e $P$. subrotunda Mast. que trata-se de $P$. silvestris.
Portanto, em ambas as listas existem erros de identificação.

$\mathrm{Na}$ área de estudo, as espécies de Passiflora ocorrem nos mais diversos tipos de vegetação (Figura 3) como Floresta Estacional Semidecidual (Mata Seca), Floresta Ombrófila Densa (Mata Úmida), Savana (Cerrado), Savana Florestada (Cerradão), Savana Estépica (Caatinga/Carrasco), Savana Estépica Arborizada (Caatinga Arbórea). Não foram registradas espécies na área de transição Savana/Floresta Estacional. espécies na área de transição Savana/Floresta Estacional.

Os representantes de Passiflora também foram citados para outras áreas serranas e úmidas do Ceará, como o maciço de Uruburetama (Santos e Figueiredo, 2018), maciço de Baturité (Silveira et al., 2020a) e o Parque Nacional de Ubajara (Pinheiro et al., 2020; Silveira et al., 2020b). As espécies desse gênero ocorrentes no Ceará foram listadas recentemente por Loiola et al. (2020), para onde foram reconhecidos 15 táxons.

Passiflora L., Sp. pl. 2: 955.1753.

Trepadeira herbácea ou lenhosa. Caule geralmente cilíndrico, raro achatado. Estípulas persistentes, lineares, ovadas, lanceoladas, raramente pinatissectas. Pecíolo geralmente glandular. Lâmina foliar, simples, inteira, oblonga ou 3-5 lobada, lobos oblongos, elípticos, ovados, oval-lanceolados, membranácea, manchas ocelares geralmente ausentes, quando presentes, duas na base e 8-12 ao longo da lâmina foliar. Brácteas lineares, oblongas, elípticas, lanceoladas, raro pinatissectas, sésseis, raro pecioladas, persistentes, raro ausentes. Flores geralmente solitárias, raro inflorescência biflora; sépalas oblongas, ovadas, lanceoladas, brancas, lilases, azuis, vermelhas, róseas, amarelas; pétalas oblongas, ovadas, brancas, lilases, azuis, vermelhas, róseas, raro ausentes; filamentos da corona dispostos em uma a seis séries; disco nectarífero geralmente presente. Fruto baga, raro cápsula, globoso, ovoide, pericarpo geralmente liso, raro 6-costado, manchas ocelares ausentes, raramente presentes, verde, vermelho, roxo ou amarelo quando maduro.

Chave de identificação das espécies de Passiflora (Passifloraceae) ocorrentes na Chapada do Araripe.

1. Filamentos da corona dispostos em uma série; fruto cápsula. 1. P. capsularis

1'. Filamentos da corona dispostos entre duas a seis séries; fruto baga.

2. Inflorescência biflora 8. P. suberosa subsp. litoralis 2'. Flores solitárias.

3. Pecíolo não glandular; disco nectarífero ausente 9. P. tricuspis

3'. Pecíolo glandular; disco nectarífero presente. 
4. Lâmina foliar inteira; cartácea ou coriácea

5. Trepadeira lenhosa; pecíolo com glândulas sésseis; pétalas vermelhas 5. P. laurifolia

5'. Trepadeira herbácea; pecíolo com glândulas estipitadas; pétalas brancas 7. P. silvestris

4'. Lâmina foliar lobada; membranácea.

6. Fruto com manchas ocelares

3. P. edulis

6' Fruto sem manchas ocelares.

7. Estípulas e brácteas pinatissectas 4. P. foetida var. foetida

7'. Estípulas lineares ou ovadas; brácteas oblongas ou elípticas

8. Pecíolo com glândulas sésseis; brácteas sésseis; pétalas lilases 2. P. cincinnata 8'. Pecíolo com glândulas estipitadas; brácteas pecioladas; pétalas róseas

6. P. picturata

1. Passiflora capsularis L., Sp. Pl. 2: 957. 1753.

Trepadeira herbácea. Caule cilíndrico. Estípulas $0,5-0,7 \mathrm{~cm}$ compr., persistentes, lineares. Pecíolo $0,6-1,8 \mathrm{~cm}$ compr., não glandular. Lâmina foliar 4,3-9,1 × 2,9-7,6 cm, 3lobada, lobos ovados, membranácea, manchas ocelares ausentes. Pedicelo 2,6-4,2 cm compr.; brácteas ausentes. Flores 2,8-3,1 cm diâm., solitárias; sépalas $1-1,2 \times 0,2-0,4 \mathrm{~cm}$, oblongas, brancas; pétalas $0,9-1,2 \times 0,2-0,4 \mathrm{~cm}$, oblongas, brancas; filamentos da corona dispostos em uma série, brancos; disco nectarífero presente. Cápsula 3,5-3.8 $\times$ 1,5-2,2 cm, ovoide, 6-costada, vermelha quando madura, manchas ocelares ausentes.

Material examinado: CEARÁ: Crato, trilha do Granjeiro, 07 $16^{\prime} 51$ 'S, 39'26'20"W, 10.II.2020, fl. e fr., F.G.L.S. Souza \& A.B. Tavares 44 (HCDAL); estrada para o Clube Granjeiro, 07¹6'30”S, 39²6’37’'W, 21.I.2014, fr., B.N.T. Walter et al. 6577 (CEN).

Passiflora capsularis foi registrada em um município em Floresta Ombrófila Densa (Mata Úmida) (Figura 3, Figura 4a-c). Floresce em fevereiro e frutifica em janeiro e fevereiro.

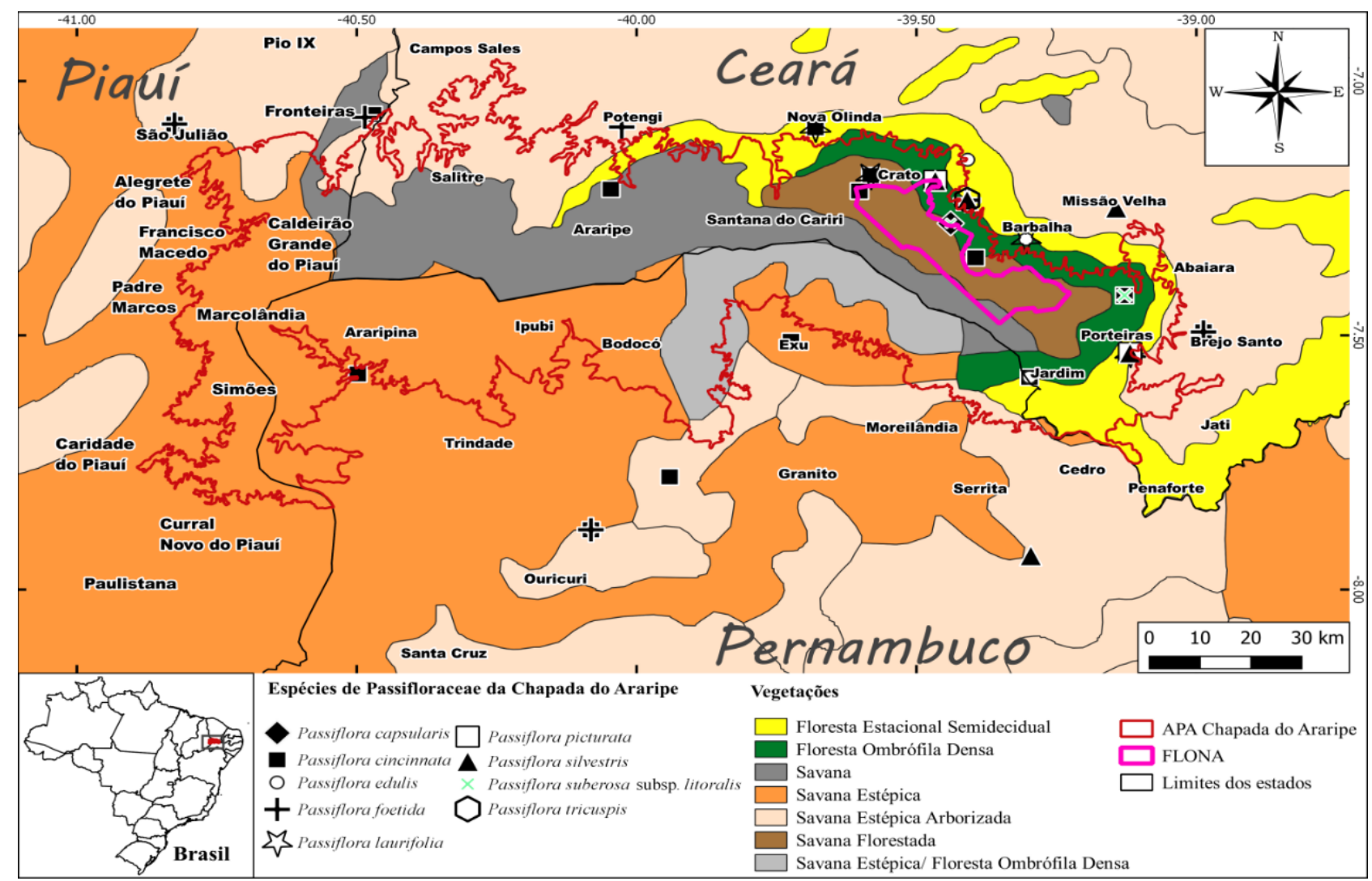

Figura 3- Distribuição de P. capsularis; P. cincinnata; P. edulis; P. foetida var. foetida; P. laurifolia; P. picturata; P. silvestris; $P$. suberosa subsp. litoralis e P. tricuspis na Chapada do Araripe, nordeste do Brasil. 
2. Passiflora cincinnata Mast., Gard. Chron. 37: 966. 1868.

Trepadeira lenhosa. Caule cilíndrico. Estípulas $0,5-0,8 \mathrm{~cm}$ compr., persistentes, lineares. Pecíolo 1,7-4,6 cm compr., com um par de glândulas sésseis. Lâmina foliar 4,2-9,3 × 7,610,8 cm, 3-5 lobada, lobos oblongos, membranácea, manchas ocelares ausentes Pedicelo 5,5-6 cm compr.; brácteas 2,9-3,4 ×1,8$2,4 \mathrm{~cm}$, oblongas, sésseis, persistentes. Flores
7,5-8,3 cm diâm., solitárias; sépalas 2,5-3,3 × $0,5-0,7 \mathrm{~cm}$, oblongas, face adaxial lilás, face abaxial verde; pétalas $3-3,4 \times 0,6-0,8 \mathrm{~cm}$ oblongas, lilases; filamentos da corona dispostos em três séries, bandeados de roxo, lilás e branco; disco nectarífero presente. Baga 4,6-5,3 cm diâm., globosa, pericarpo liso, verde, manchas ocelares ausentes.

Material examinado selecionado: CEARÁ: Araripe, Sítio Arruda, 07²1'25”S, 4004'61”W,
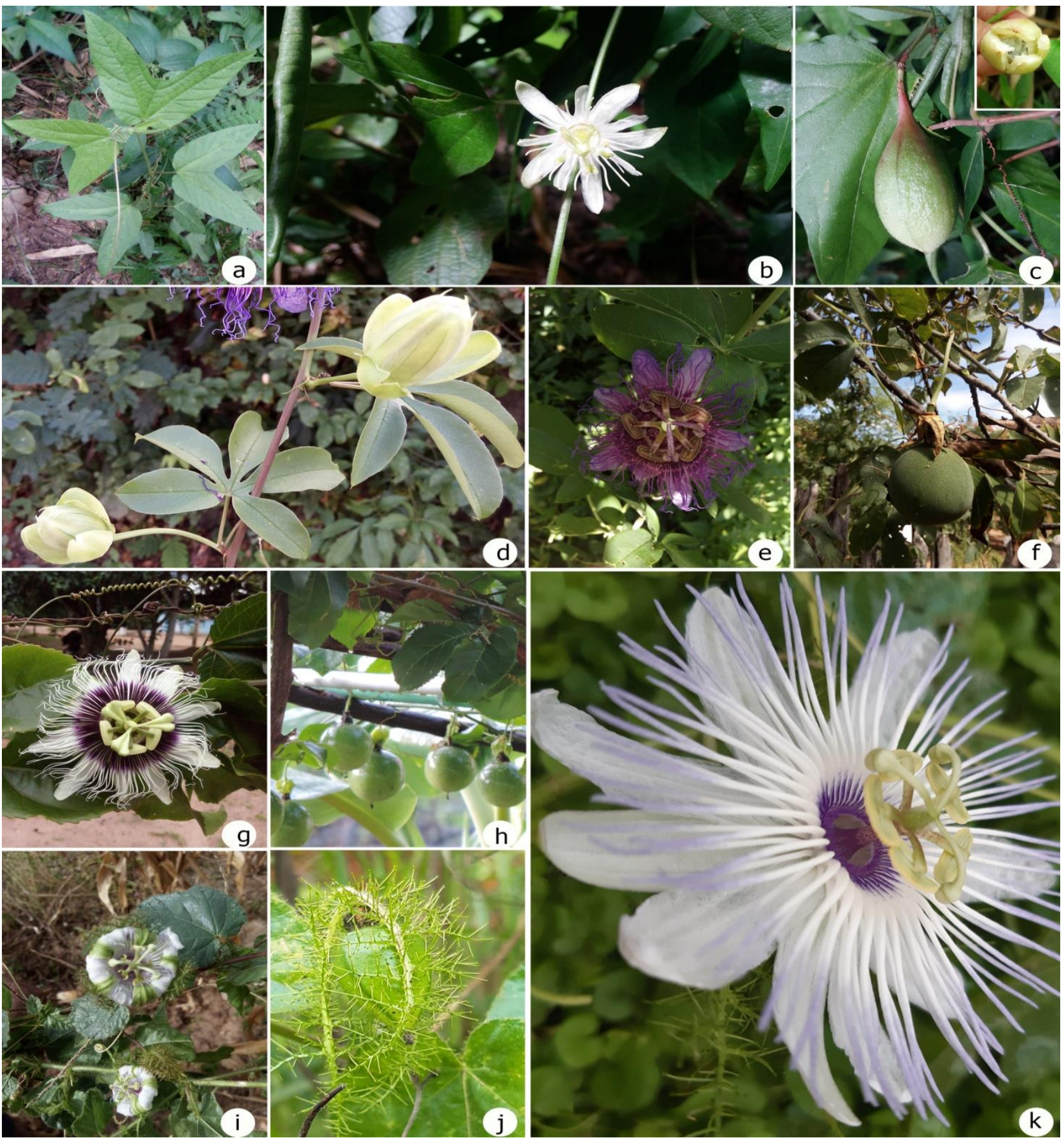

Figura 4- Passifloraceae s.s. na Chapada do Araripe, nordeste do Brasil - a-c. Passiflora capsularis - a. folha; b. flor; c. fruto e deiscência do fruto. d-f. P. cincinnata - d. folhas e botões; e. flor; f. fruto. g-h. $P$. edulis - g. folhas e flor; h. folhas e frutos. i-k. P. foetida var. foetida - i. folhas e flores; j. fruto evidenciando brácteas pinatissectas; $\mathrm{k}$. flor evidenciando androginóforo. (h, j, k. ICS Neves). 
22.XII.2016, fl. e fr., A.A. Silva s.n. (HCDAL 12661). Barbalha, Floresta Nacional do AraripeApodi, 07³4'54'S, 39³9'44”W, 31.III.2013, fl. e fr., L.Z.O. Campos; Ribamar \& Damasio 117 (PEUFR). Brejo Santo, ASV Igrejinha 07049'33”S, 38 58'27'W, 28.IV.2015, fr., $M$. Oliveira 6074 (HUEFS). Crato, Sítio Baixa do Maracujá, 07¹2'44”S, 39³1'34”W, 13.II.2020, bot., F.G.L.S. Souza \& A.B. Tavares 49 (HCDAL). Jardim, Sítio Berê, 01.XI.2002, fl. M.A.P. Silva (HCDAL 3224). Nova Olinda, 16.IV.2012, fl., D.A. Ribeiro 9276 (HCDAL). Missão Velha, Sítio Pinheira, 0 $7^{\circ} 25^{\prime} 28^{\prime \prime}$, 3907'34"W, 11.II.2020, bot., F.G.L.S. Souza \& I.C.S. Neves 46 (HCDAL). Porteiras, estrada Porteiras a Jamacaru, $07^{\circ} 28^{\prime} 55^{\prime} \mathrm{S}, 39^{\circ} 07^{\prime} 52^{\prime \prime} \mathrm{W}$, 08.III.2020, bot., F.G.L.S. Souza \& I.C.S. Neves 65 (HCDAL). Santana do Cariri, Cancelão, 07021'63”S，3960'19”'W，20.VI.1966，fr., E. Melo 9819 (HUEFS). PERNAMBUCO: Araripina, Chapada do Araripe, 07 57'61"S, 4049'82"W, 19.XII.1992, fl. e fr., A.M. Miranda et al. 645 (HST). Bodocó, antes do povoado de Serrolândia, na estrada de terra para Araripina, 07077'83”S, 3994'11'W, 10.VI.1992, fr., $R$. Pereira et al. 731(IPA). Exu, distrito de
Tiomorante, Serra do Ingá, 07 51'19”S, 39²'42”W, 05.V.2005, fl. e fr., R. Pereira, O. Cano \& C. Ferreira (IPA 69989). Ouricuri, a 32 $\mathrm{km}$ da cidade de Ouricuri, 07 $88^{\prime} 25^{\prime \prime} \mathrm{S}$, 4008'16”W, 05.V.1971, fl., Academia Brasileira de Ciências 515 (IPA). PIAUÍ: Fronteiras, estrada que liga Padre Marcos à Fronteiras, às margens da estrada, $07^{\circ} 06^{\prime} 16^{\prime \prime} \mathrm{S}, 40^{\circ} 41^{\prime} 10^{\prime \prime} \mathrm{W}$, 17.VI.2020, bot., F.G.L.S. Souza \& V.S. Januário 76 (HCDAL). São Julião, povoado de Mandacaru, às margens da estrada, $07^{\circ} 06^{\prime} 56^{\prime \prime} \mathrm{S}, 40^{\circ} 47^{\prime} 07^{\prime \prime} \mathrm{W}$, 17.VI.2020, bot., F.G.L.S. Souza \& V.S. Januário 75(HCDAL).

Passiflora cincinnata foi registrada em 15 municípios em Floresta Estacional Semidecidual (Mata Seca), Floresta Ombrófila Densa (Mata Úmida), Savana (Cerrado), Savana Florestada (Cerradão), Savana Estépica (Carrasco), Savana Estépica Arborizada (Caatinga Arbórea) (Figura 3, Figura 4d-f, Figura 5a). Foram realizadas coletas inéditas nos municípios: Porteiras (CE), Fronteiras (PI) e São Julião (PI). Floresce e frutifica praticamente o ano todo. Esta espécie é conhecida popularmente por maracujá, maracujá do mato e maracujá de estalo.
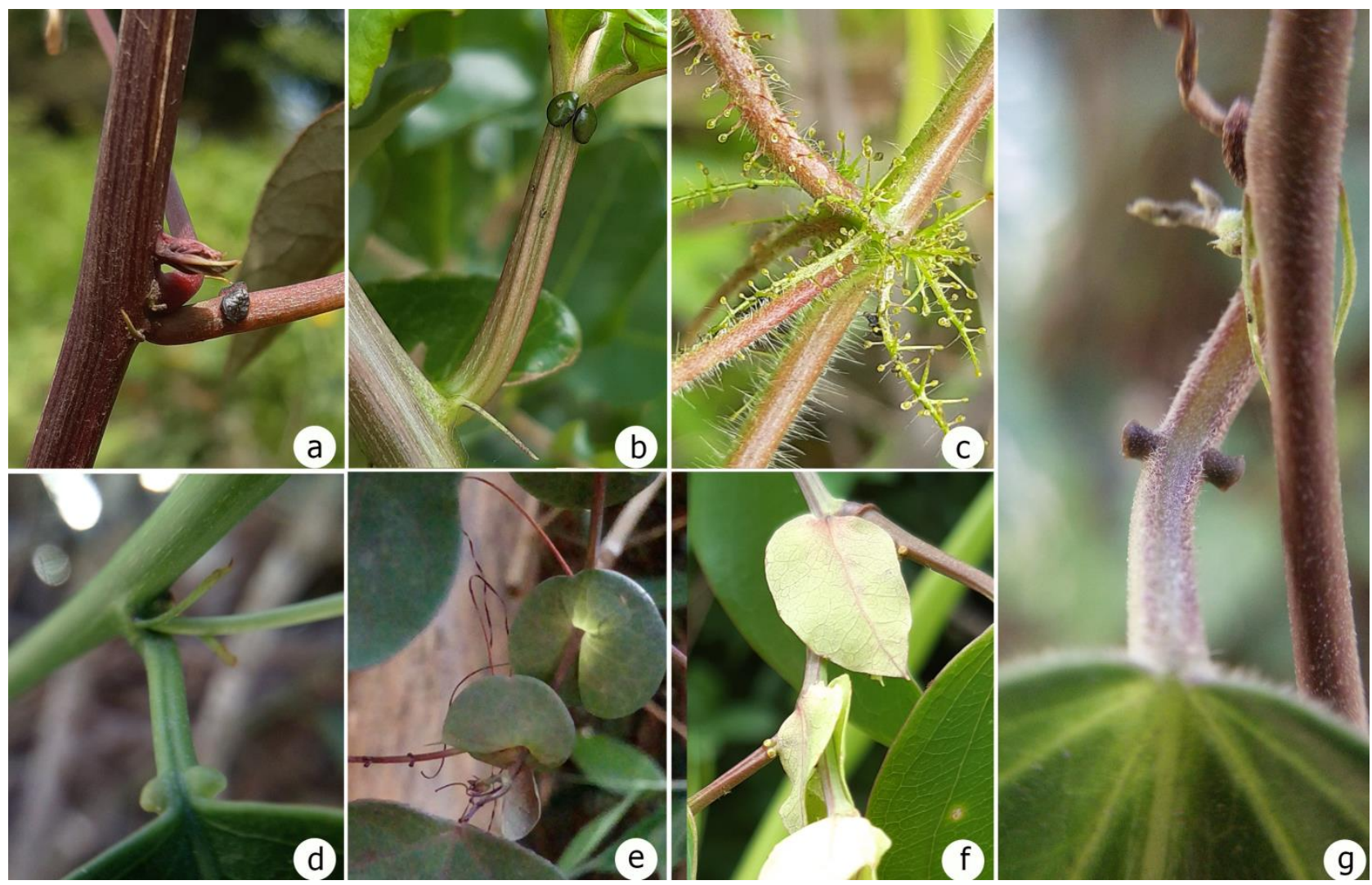

Figura 5- Glândulas peciolares de Passiflora ocorrentes na Chapada do Araripe, nordeste do Brasil. a. P. cincinnata, b. P. edulis, c. P. foetida var. foetida, d. P. laurifolia, e. P. picturata, f. P. silvestris, g. $P$. suberosa subsp. litoralis. (a-c, f- I.C.S. Neves). 
3. Passiflora edulis Sims, Bot. Mag. 45: t.1989. 1818.

Trepadeira lenhosa. Caule cilíndrico Estípulas $\quad 0,7-0,9 \mathrm{~cm}$ compr., persistentes, lineares. Pecíolo 1,9-2,1 cm compr., com um par de glândulas sésseis. Lâmina foliar $6,8-11,5 \times$ 9,5-15,4 cm, 3-lobada, lobos elípticos, membranácea, manchas ocelares ausentes. Pedicelo 2,7-3,3 cm compr.; brácteas 2,8-3,2 $\times 1,8-2 \mathrm{~cm}$, elípticas, sésseis, persistentes. Flores 8,3-9,1 cm diâm., solitárias; sépalas 3,6-4,3 $\times 1,2-1,8 \mathrm{~cm}$, oblongas, face adaxial branca, face abaxial verde; pétalas $3,2-3,5 \times 0,7-0,9 \mathrm{~cm}$ oblongas, brancas; filamentos da corona dispostos em 3 séries, bandeados de roxo e branco; disco nectarífero presente. Baga 4,3-6,3 cm diâm., globosa, pericarpo liso, amarela quando madura, manchas ocelares brancas.

Material examinado selecionado: CEARÁ: Barbalha, Sítio Macaúba, 10.XI.2016, fl., I.V. Silva (HCDAL 12675). Crato, Sítio Quebra, 0709'16"S, 39²4'29'W, 16.III.2020. bot., F.G.L.S. Souza 71 (HCDAL). Jardim, casa de Dona Odete, 15.V.2008, fl. e fr., L.K.P. Dutra \& F.R. Silva 3848 (HCDAL). PERNAMBUCO: Ouricuri, Lagoa Comprida, 30.V.2003, fl., s.n. 73 (UFP).

Passiflora edulis foi registrada em quatro municípios, em Floresta Estacional Semidecidual (Mata Seca), Floresta Ombrófila Densa (Mata úmida), Savana (Cerrado) e Savana Estépica (Carrasco) (Figura 3, Figura 4g-h, Figura 5b). Floresce em março, maio, agosto e novembro e frutifica em fevereiro e maio. Conhecida popularmente por maracujá e maracujá de ponche.

4. Passiflora foetida $\mathrm{L}$. var. foetida, Sp. Pl. 2: 959. 1753.

Trepadeira herbácea. Caule cilíndrico. Estípulas $0,4-0,9 \times 1,2-1,8 \mathrm{~cm}$, persistentes, pinatissectas. Pecíolo 1-5,5 cm compr., glandular por toda a sua extensão. Lâmina foliar 3-10,6 × 2,7-3,9 cm, 3-lobada, lobos ovados, membranácea, manchas ocelares ausentes. Pedicelo 4-7,6 cm compr.; brácteas 2,5-4,7 $\times$ 1,5-3,5 cm, pinatissectas, sésseis, persistentes. Flores 3-4,9 cm diâm., solitárias; sépalas 0,9-1,2 $\times 0,3-0,5 \mathrm{~cm}$, oblongas ou ovadas, face adaxial branca ou azul, face abaxial verde; pétalas $0,9-1,3$ $\times 0.4-0,6 \mathrm{~cm}$, oblongas ou ovadas, brancas ou azuis; filamentos da corona dispostos em cinco séries, brancos ou bandeados de branco e azul; disco nectarífero presente. Baga 2-3,5 cm diâm., 13.II.2020, fr., F.G.L.S. Souza \& A.B. Tavares 47 (HCDAL). Nova Olinda, Sítio Zabelê, globosa, pericarpo liso, verde, manchas ocelares ausentes.

Material examinado selecionado: CEARÁ: Brejo Santo, Serra Canabrava, Jazida Canabravinha, $\quad 07^{\circ} 49^{\prime} 33^{\prime \prime} \mathrm{S}, \quad 38^{\circ} 98^{\prime} 72^{\prime \prime} \mathrm{W}$ 05.V.2016, fr., A.P. Fontana 9610 (HUEFS). Crato, Sítio Almécegas, $07^{\circ} 12^{\prime} 30^{\prime \prime} \mathrm{S}, 39^{\circ} 26^{\prime} 35^{\prime \prime} \mathrm{W}$, 27.II.2020, fl., F.G.L.S. Souza \& M.G.L. Sampaio 55 (HCDAL). Potengi, próximo à cidade, 0709'05"S, 4002'66"W, 10.XII.1980, bot., P. Martins (EAC). PERNAMBUCO: Ouricuri, Bacia do rio Brigida, 500 metros da ponte sobre o Rio Ur, 0788'25"S，4008'16"W, 12.VII.1994, fl., F.S. Pinto 142 (EAC). PIAUÍ: Fronteiras, às margens da estrada, $07^{\circ} 05^{\prime} 02^{\prime \prime} S, 40^{\circ} 33^{\prime} 55^{\prime \prime} \mathrm{W}$, 17.VI.2020, fr., F.G.L.S. Souza \& V.S. Januário 73 (HCDAL). São Julião, às margens da estrada, 07 07'13"S, 40 48'56"W, 17.VI.2020, fr., F.G.L.S. Souza \& V.S. Januário 74 (HCDAL).

Passiflora foetida var. foetida foi registrada em seis municípios na Floresta Estacional Semidecidual (Mata Seca), Floresta Ombrófila Densa (Mata úmida), Savana (Cerrado), Savana Estépica (Carrasco), Savana Estépica Arborizada (Caatinga Arbórea) (Figura 3, Figura 4i-k, Figura 5c). Foram realizadas coletas inéditas nos municípios: Fronteiras (PI) e São Julião (PI). Floresce em janeiro, fevereiro, julho, novembro e dezembro e frutifica em maio, novembro e dezembro. Conhecida popularmente por maracujá de estalo ou maracujá de estralo.

\section{Passiflora laurifolia L., Sp. Pl. 2: 956. 1753.}

Trepadeira lenhosa. Caule cilíndrico. Estípulas $0,4-0,5 \mathrm{~cm}$ compr., persistentes, lineares. Pecíolo 0,5-0,9 cm compr., com um par de glândulas sésseis. Lâmina foliar 6,9-9,7 × 3,3$4,3 \mathrm{~cm}$, inteira, oblonga, coriácea, manchas ocelares ausentes. Pedicelo 1-1,2 cm compr.; brácteas 2,6-3,1 × 0,8-1,1 cm, oblongas, sésseis, persistentes. Flores 8-11,2 cm diâm., solitárias; sépalas $3,1-4,9 \times 0,9-1,3 \mathrm{~cm}$, oblongas, vermelhas; pétalas $2,9-4,7 \times 0,6-1,1 \mathrm{~cm}$, oblongas, vermelhas; filamentos da corona dispostos em seis séries, bandeados de vermelho, branco, lilás, azul e roxo; disco nectarífero presente. Baga 4-4,3 cm diâm., globosa, pericarpo liso, amarela quando madura, manchas ocelares ausentes.

Material examinado selecionado: CEARÁ: Barbalha, casa de Senhor Mundô, 07.XII.2011, fr., A.C.B. Santos (HCDAL 7722). Crato, Sítio Baixa do Maracujá, $07^{\circ} 12^{\prime} 59^{\prime \prime} \mathrm{S}, 39^{\circ} 31^{\prime} 35^{\prime \prime} \mathrm{W}$, 07'17'33"S, 3959'36”'W, 14.II.2013, fl., A.B.M. Lima-Neto (EAC 54392). Porteiras, estrada 
Porteiras a Jamacaru, $07^{\circ} 29^{\prime} 14^{\prime \prime} \mathrm{S}, 39^{\circ} 08^{\prime} 40^{\prime \prime} \mathrm{W}$, 08.III.2020, fr., F.G.L.S. Souza \& I.C.S. Neves 58 (HCDAL).

Passiflora laurifolia foi registrada em quatro municípios em Floresta Estacional Semidecidual(Mata Seca), Floresta Ombrófila Densa (Mata úmida) e Savana Florestada (Cerradão) (Figura 3, Figura5 d, Figura 6a-b). Foi realizada coleta inédita no município de Porteiras (CE). Seus frutos são utilizados no preparo de sucos. Floresce em janeiro, fevereiro, maio, novembro e frutifica em janeiro a março, maio e dezembro. Conhecida popularmente por maracujá e maracujá peroba.

6. Passiflora picturata Ker Gawl., Bot. Reg. 8: t. 673. 1822.

Trepadeira lenhosa. Caule cilíndrico. Estípulas 1,2-2,3 $\times 1-2,5 \mathrm{~cm}$, persistentes, ovadas. Pecíolo 1,7-4,2 cm compr., com um par de glândulas estipitadas. Lâmina foliar 2,8-7 × 44,9 cm, 3-lobada, lobos ovados, membranácea, manchas ocelares ausentes. Pedicelo $5,9-8,5 \mathrm{~cm}$ compr.; brácteas 2,1-2,8 × 1,9-2,3 cm, elípticas, pecioladas, caducas. Flores 3,9-4,5 cm diâm., solitárias; sépalas $1,2-1,5 \times 0,4-0,5 \mathrm{~cm}$, oblongas, face adaxial rósea, face abaxial verde; pétalas $1-$ $1,2 \times 0,3-0,5 \mathrm{~cm}$, oblongas, róseas; filamentos da corona dispostos em duas séries, bandeados de roxo e branco; disco nectarífero presente. Baga 4,8-5,4 cm diâm., globosa, pericarpo liso, verde, manchas ocelares ausentes.

Material examinado selecionado: CEARÁ: Crato, Sítio Boa Vista, $07^{\circ} 11^{\prime} 46^{\prime \prime}$, 39²7'44” W, 27.II.2020, fr., F.G.L.S. Souza \& M.G.L. Sampaio 51 (HCDAL); trilha do Belmonte, Floresta Nacional do Araripe, $07^{\circ} 14^{\prime} 00^{\prime \prime} \mathrm{S}, 39^{\circ} 28^{\prime} 00^{\prime \prime} \mathrm{W}$, 20.VII.2015, fl., J.E.G. Santos \& D.L. Silva (HCDAL 12217). Porteiras, estrada Porteiras a Jamacaru, 07 29'03'S, 3907'57'W, 08.III.2020,

fr., F.G.L.S. Souza \& I.C.S. Neves 62 (HCDAL). PERNAMBUCO: Exu, 15.II.2013, fl., M.E. Saraiva 72 (HCDAL).

Passiflora picturata foi registrada em dois municípios em Floresta Estacional Semidecidual (Mata Seca) e Floresta Ombrófila Densa (Mata úmida) (Figura 3, Figura 5e, Figura 6c-d). ). Foi realizada coleta inédita no município de Porteiras (CE). Floresce em janeiro, fevereiro e julho e frutifica em fevereiro e março. Conhecida popularmente por maracujá do agreste.

7. Passiflora silvestris Vell., Fl. Flumin. Icon. 9: t. 74. 1831.
Trepadeira herbácea. Caule cilíndrico. Estípulas $0,7-2,1 \times 1,3-4,3 \mathrm{~cm}$, persistentes, lanceoladas. Pecíolo 0,6-1,2 cm compr., com um par de glândulas estipitadas. Lâmina foliar 4,7-8,7 $\times 1,3-4,3 \mathrm{~cm}$, inteira, oblonga, cartácea, manchas ocelares ausentes. Pedicelo 5,5-6,2 cm compr.; brácteas 1,4-1,6 × 1-1,3 cm, lanceoladas, sésseis, persistentes. Flores $6,7-7,6 \mathrm{~cm}$ diâm., solitárias; sépalas $2,6-3,2 \times 0,4-0,5 \mathrm{~cm}$, lanceoladas, face adaxial branca, face abaxial verde; pétalas 2,3-2,8 $\times 0,3-0,4 \mathrm{~cm}$, oblongas, brancas; filamentos da corona dispostos em duas séries, brancos; disco nectarífero presente. Baga 3,5-4,2 × 1,9-3,2 cm, ovoide, 6-costada, verde, manchas ocelares ausentes.

Material examinado selecionado: CEARÁ: Barbalha, Floresta Nacional do Araripe, 07'31'11"S, 39³0'41'”, 30.I.2013, fr., L.B. Silva (IPA 88334). Crato, Sítio Boa Vista 0701'46"S, 39²7'44”'W, 27.II.2020, fr., F.G.L.S. Souza \& M.G.L. Sampaio 53 (HCDAL). Missão Velha, estrada Porteiras a Jamacaru, $07^{\circ} 28^{\prime} 20^{\prime \prime}$, $39^{\circ} 07^{\prime} 24$ 'W, 08.III.2020, fr., F.G.L.S. Souza \& I.C.S. Neves 67 (HCDAL). Porteiras, estrada Porteiras a Jamacaru, $07^{\circ} 29^{\prime} 05^{\prime \prime} \mathrm{S}, 39^{\circ} 07^{\prime} 57^{\prime \prime} \mathrm{W}$, 08.III.2020, fl. e fr., F.G.L.S. Souza \& I.C.S. Neves 60 (HCDAL). PERNAMBUCO: Serrita, Serra do Gravatá, beira d'água nascente, 07093'33”S, 39²9'57'W, 04.09.2014, fl., A.P. Fontana et al. 8441 (HUEFS).

Passiflora silvestris foi registrada em cinco municípios, em Floresta Estacional Semidecidual (Mata Seca), Floresta Ombrófila Densa (Mata Úmida) e Savana Estépica Arborizada (Caatinga Arbórea) (Figura 3, Figura 5f, Figura 6e-h). Foram realizadas coletas inéditas nos municípios: Missão Velha (CE) e Porteiras (CE). Floresce em janeiro, fevereiro, março, maio, setembro e novembro e frutifica em janeiro, fevereiro, março, maio e dezembro.

8. Passiflora suberosa subsp. litoralis (Kunth) Port.-Utl. ex M.A.M. Azevedo, Baumgratz \& Gonç.-Estev. Phytotaxa 53: 47. 2012.

Trepadeira herbácea. Caule achatado. Estípulas $\quad 0,4-0,6 \mathrm{~cm}$ compr., persistentes, lineares. Pecíolo 1,3-2,2 cm compr., com um par de glândulas estipitadas. Lâmina foliar 5,5-16,6 × 3,1-8,8 cm, 3-lobada, lobos oval-lanceolados, membranácea, manchas ocelares ausentes. Pedicelo 2,7-2,9 cm compr.; brácteas $0,4-0,5 \mathrm{~cm}$ compr., lineares, caducas. Flores 1,8-2 cm diâm., inflorescência biflora; sépalas $0,6-0,7 \times 0,2-0,4$ 

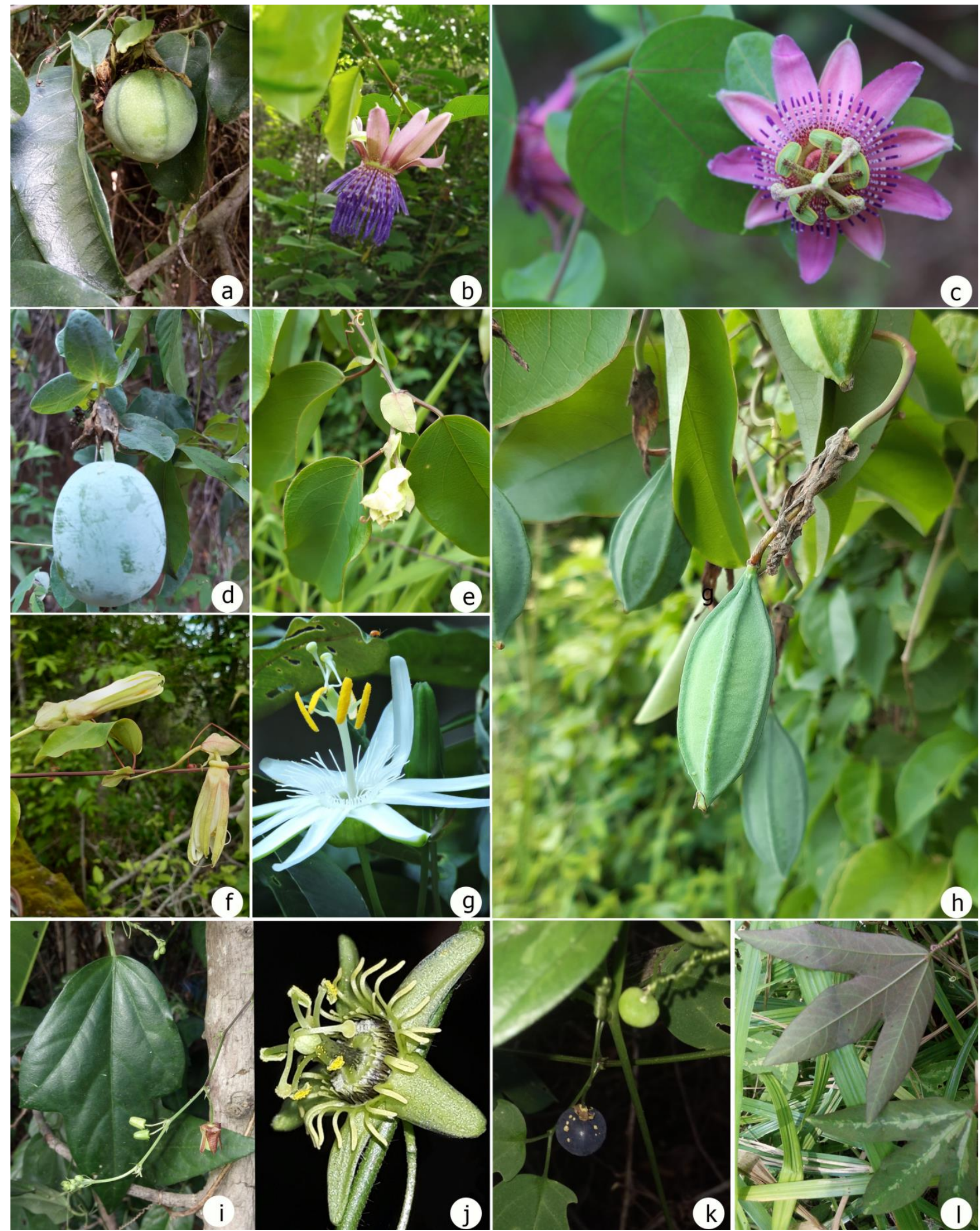

Figura 6- Passifloraceae s.s. na Chapada do Araripe, nordeste do Brasil - a-b. Passiflora laurifolia - a. folha e fruto; b. folha e flor. c-d. P. picturata - d. folha e flor; e. brácteas e fruto. e-h. P. silvestris - e. folhas e estípulas; f. botões; g. flor; h. frutos. i-k. P. suberosa subsp. litoralis - i. folhas e botões; j. flor; k. frutos. 1. Passiflora tricuspis - folhas (b. FWS Machi, c. VS Sampaio, d-f, h ICS Neves, g, j. RT Queiroz). 
$\mathrm{cm}$, oblongas, amarela na face adaxial, verde na face abaxial; pétalas ausentes; filamentos da corona dispostos em duas séries, série externa verde-arroxeada, série interna roxa.; disco nectarífero presente. Baga 1,8-2 cm diâm., globosa, pericarpo liso, roxa quando madura, manchas ocelares às vezes presente, brancas.

Material examinado selecionado: CEARÁ: Crato, trilha do Granjeiro, $07^{\circ} 16{ }^{\prime} 50^{\prime}$ 'S, $39^{\circ} 26^{\prime} 20^{\prime \prime} W$, 13.III.2020, fl. e fr., F.G.L.S. Souza \& L.C. Silva 70 (HCDAL). Missão Velha, Sítio Pinheira, 07²5'19'S, 3907'43”W, 14.VI.2020, fl. e fr., F.G.L.S. Souza \& V.L. Sampaio 72 (HCDAL).

Passiflora suberosa subsp. litoralis foi registrada em dois municípios, em Floresta Ombrófila Densa (Mata Úmida) (Figura 3, Figura $5 \mathrm{~g}$, Figura 6i-k). Foi realizada coleta inédita no município de Missão Velha (CE). Floresce e frutifica em março e junho.

9. Passiflora tricuspis Mast., Fl. bras. 13(1): 587. 1872.

Trepadeira herbácea. Caule achatado. Estípula 0,2-0,3 cm compr., persistentes, lineares. Pecíolo 1,8-3 cm compr., não glandular. Lâmina foliar 5,7-7,5 × 7,1-9,3 cm, 3-lobada, lobos oblongos, cartácea, duas manchas ocelares na base e 8-12 ao longo da lâmina foliar. Pedicelo 1,6-3,8 $\mathrm{cm}$ compr.; brácteas $0,1-0,2 \mathrm{~cm}$, lineares, persistentes. Flores 2,3-2,8 cm diâm., solitárias; sépalas $0,8-1,1 \times 0,3-0,5 \mathrm{~cm}$, oblongas, brancas; pétalas $0,7-0,8 \times 0,2-0,4 \mathrm{~cm}$, oblongas, brancas; filamentos da corona dispostos em duas séries, brancos; disco nectarífero ausente. Baga 0,8-1.8 $\mathrm{cm}$, globosa, pericarpo liso, nigrescente quando madura, manchas ocelares ausentes.

Material examinado: Crato, Floresta Nacional do Araripe, Guaribas, 07²3'41'S, 39 40'94"W, 14.I.1999, fl. e fr., A.M. Miranda \& D. Lima 3139 (HST); Sítio Guaribas, 28.III.200, fr., F.S. Calvalcanti (EAC).

Passiflora tricuspis foi registrada em um município em Floresta Estacional Semidecidual (Mata Seca), (Figura 3, Figura 61). Floresce e frutifica em janeiro. Conhecida popularmente por maracujá de estalo.

Considerando os dados do Flora do Brasil (2020 em construção) em relação ao número de espécies de Passiflora citadas para o Ceará (18 spp.), Pernambuco (18 spp.) e Piauí (11 spp.), há uma considerável riqueza de espécies na Chapada do Araripe para os dois primeiros estados, correspondendo a $50 \%$ e $45 \%$ respectivamente. No território do Piauí ocorre $18 \%$ dos táxons, demonstrando uma deficiência em coletas no referido estado.

As informações obtidas neste estudo evidenciou que praticamente inexistem coletas na parte da Chapada do Araripe inserida no estado do Piauí, revelando a importância de maiores esforços de coleta para esta área. O município do Crato tem o maior número de coletas e também o registro de todas as espécies reconhecidas para a Chapada do Araripe.

As espécies ocorrem nos mais diversos tipos de vegetação, mas têm preferência pela Floresta Ombrófila Densa (Mata Úmida), corroborando a nossa hipótese. Observou-se que a fenologia das espécies é muito variável, no entanto, Passiflora cincinnata floresce e frutifica praticamente $\mathrm{o}$ ano todo.

\section{Agradecimentos}

À FUNCAP (Fundação Cearense de Apoio ao Desenvolvimento Científico e Tecnológico) pela bolsa de mestrado concedida à primeira autora. À Iranilda Cordeiro Sampaio Neves, Valéria da Silva Sampaio, Rubens Teixeira de Queiroz e Francisco Walison dos Santos Machi pelas fotografias cedidas. Maria Iracema Bezerra Loiola agradece ao $\mathrm{CNPq}$ pela bolsa de produtividade concedida (Processo $\mathrm{N}^{\circ}$ 304099/2017-1).

\section{Referências}

Agra, M.F., Barbosa, M.R.V., Stevens, W.D., 2004. Levantamento florístico preliminar do pico do Jabre, Paraíba, Brasil. In: Porto, K.C., Cabral, J.J.P., Tabarelli, M. (Orgs.). Brejos de altitude em Pernambuco e Paraíba: história natural, ecologia e conservação. Série Biodiversidade. Ministério do Meio Ambiente, Brasília, pp. 123-138.

Alcântara, M.C., Lucena, C.M., Lucena, R.F.P., Cruz, D.D., 2020. Ethnobotany and Management of Dimorphandra gardneriana in a Protected Area of Chapada do Araripe Semiarid Ceará, Northeastern Brazil. Environmental Management 65, 420-432.

Bastos, F.H., Cordeiro, A.B.N., Macedo, E.F., Azevedo, R.E.S., 2016. A gestão ambiental nas paisagens da bacia do Araripe no Estado do Ceará. Confins. Revista Franco-brasileira de Geografia 29, 1-16.

Bezerra, L.M.C., Fredo, C.E., Meletti, L.M.M., 2016. Cultivo de maracujá-amarelo no estado 
de São Paulo: principais características a partir do Levantamento das Unidades de Produção Agropecuária, ano-safra 2007/2008. Informações Econômicas 46, 35-46.

Borges, K.F., Milward-de-Azevedo, M.A., 2017. Passifloraceae sensu stricto do Parque Estadual Cachoeira da Fumaça, Espírito Santo, Brasil. Rodriguésia 68, 1939-1949.

Costa, I.R., Araújo, F.S., Lima-Verde, L.W., 2004. Flora e aspectos autoecológicos de um encrave de cerrado na Chapada do Araripe, Nordeste do Brasil. Acta Botanica Brasilica 18, 759-770.

Costa, E.C.S., Nunes, T.S., Melo, J.I.M., 2015. Flora da Paraíba, Brasil: Passifloraceae sensu stricto. Rodriguésia 66, 271-284.

Ferreira, J.C.V., Praxedes, B.D.A.C., Chaves, M.S., Lima, Z.M.C., 2016. Atividade de campo e o ensino de Geografia Física: uma proposta de roteiro científico para a Chapada do Araripe, Ceará, NE do Brasil. Sociedade e Território 28, 174-192.

Ferreira-Silva, C., Ribeiro, S.C., Alcântara, E.P., Ávila, R.W., 2019. Natural history of the rare and endangered snake Atractus ronnie serpentes: Colubridae) in northeastern Brazil. Phyllomedusa 18, 77-87.

Figueiredo, M.A. 1997. A cobertura vegetacional do Ceará: Unidades fitoecológicas. In: Ceará, Atlas do Ceará. Edições IPLANCE, Fortaleza, pp. 28-29.

Flora do Brasil 2020 (em construção), 2020. Jardim Botânico do Rio de Janeiro. [Online]. Disponível: http://floradobrasil.jbrj.gov.br. Acesso: 08 jun. 2020.

Gonçalves, E.G., Lorenzi, H., 2011. Morfologia vegetal organografia e dicionário ilustrado de morfologia das plantas vasculares. Ed. Instituto Plantarum, Nova Odessa.

Guerra, M.D.F., Souza, M.J.N., Silva, E.V., 2020. Veredas da Chapada do Araripe: subespaços de exceção no semiárido do estado do Ceará, Brasil. Ateliê Geográfico 14, 51-66.

IBGE. Instituto Brasileiro de Geografia e Estatística, 2012. Manual técnico da vegetação brasileira. [Online]. Disponível: ftp://geoftp.ibge.gov.br/documentos/recursos_ naturais/manuais_tecnicos/manual_tecnico_ve getacao_brasileira.pdf>. Acesso: 08 jun. 2020.

ICMBIO. Instituto Chico Mendes de Conservação da Biodiversidade, 2020. Unidades de Conservação no Brasil. [Online]. Disponível: https://uc.socioambiental.org/ptbr/arp/1194. Acesso: 12 jun. 2020.

Imig, D.C., Milward-de-Azevedo, M.A., Cervi, A.C., 2018. Passifloraceae sensu stricto de Minas Gerais, Brasil. Rodriguésia 69, 17011735.

IPNI. The International Plant Names Index, 2020. The Royal Botanic Gardens, Kew. [Online]. Disponível: http://www.ipni.org/. Acesso: 12 jun. 2020.

Loiola, M.I.B., Araújo, F.S., Lima-Verde, L.W., Souza, S.S.G., Matias, L.Q., Menezes, M.O.T., Soares Neto, R.L., Silva, M.A.P., Souza, M.M.A., Mendonça, A.M., Macêdo, M.S., Oliveira, S.F., Sousa, R.S., Balcázar, A.L., Crepaldi, C.G., Campos, L.Z.O., Nascimento, L.G.S., Cavalcanti, M.C.B.T., Oliveira, R.D., Silva, T.C., Albuquerque, U.P., 2015. Flora da Chapada do Araripe. In: U.P. Albuquerque, M.V. Meiado (Eds.), Sociobiodiversidade na Chapada do Araripe. NUPEEA, Recife, pp. 103-148.

Loiola, M.I.B., Ribeiro, R.T.M., Sampaio, V.S., Souza, E.B. (Org.), 2020. Diversidade de angiospermas do Ceará. Edições HUVA, Sobral. Disponível: http://www. uvanet.br /edicoes_uva/gera_xml.php?arquivo=diversida de_angiospermas_ceara_02122020. Acesso: 22 dez. 2020.

Loiola, M.I.B., Araújo, F.S., Lima-Verde, L.W., Souza, S.S.G., Matias, L.Q., Menezes, M.O.T., Soares Neto, R.L., Silva, M.A.P., Souza, M.M.A., Mendonça, A.M., Macêdo, M.S., Oliveira, S.F., Sousa, R.S., Balcázar, A.L., Crepaldi, C.G., Campos, L.Z.O., Nascimento, L.G.S., Cavalcanti, M.C.B.T., Oliveira, R.D., Silva, T.C., Albuquerque, U.P., 2015. Flora da Chapada do Araripe. In: U.P. Albuquerque, M.V. Meiado (Eds.), Sociobiodiversidade na Chapada do Araripe. NUPEEA, Recife, pp. 103-148.

Loiola, M.I.B., Ribeiro, R.T.M., Sampaio, V.S., Souza, E.B. (Org.), 2020. Diversidade de 
angiospermas do Ceará. Edições HUVA, Sobral. Disponível: http://www. uvanet.br /edicoes_uva/gera_xml.php?arquivo=diversida de_angiospermas_ceara_02122020. Acesso: 22 dez. 2020.

Macêdo, D.G., Ribeiro, D.A., Coutinho, H.D.M., Menezes, I.R.A., Souza, M.M.A., 2015. Práticas terapêuticas tradicionais: uso e conhecimento de plantas do cerrado no estado de Pernambuco (Nordeste do Brasil). Boletín Latinoamericano y del Caribe de Plantas Medicinales y Aromáticas 14, 491-508.

Milward-de-Azevedo, M.A., 2018. Histórico de Passiflora L. com enfoque no subgênero Decaloba (DC.) Rchb. (Passifloraceae sensu stricto). Diversidade e Gestão 2, 36-45.

Novaes, R.L.M., Felix, S., Souza, R.F., 2013. Save Caatinga from drought disaster. Nature 498, 170.

Novaes, R.L.M., Laurindo, R.S., 2014. Morcegos da Chapada do Araripe, Nordeste do Brasil. Papéis Avulsos de Zoologia 54, 315-328.

Pereira, R.C.A., Lima, V.C., Silva, R.S., Silva, S.Z., 1993. Lista das espécies arbóreas e arbustivas ocorrentes nos principais brejos de altitude de Pernambuco. Série Documentos, 22. Instituto Agronômico de Pernambuco, Recife.

Pereira, T.T.C., Reinaldo Duque Brasil, R.D. P. Oliveira, A.M., Poeiras, L.M., Almeida, I.C.C., 2020. Propostas e desafios para definição de áreas prioritárias para conservação da biodiversidade no norte de Minas Gerais (Brasil), Revista Brasileira de Meio Ambiente 8, 53-69.

Pinheiro, L.F., Alves, J.C., Xavier, S.A.S., Cavalcante, A.V., Loiola, M.I.B., 2020. Diversidade de Lianas e Trepadeiras do Parque Nacional de Ubajara, Ceará, Brasil. Revista Brasileira de Geografia Física 13, 1675-1687.

Queiroz, R.T., Cordeiro, L.S., Sampaio, V.S., Ribeiro, R.T.M., Loiola, M.I.B., 2018. A Região Nordeste. In: Coradin, L., Camillo, J., Pareyn, F.G.C. (Eds.) Espécies nativas da flora brasileira de valor econômico atual ou potencial: plantas para $\mathrm{o}$ futuro: região Nordeste. Ministério do Meio Ambiente, Brasília, pp. 73-104.
Reflora, 2020. Herbário Virtual. Disponível em: [Online] Disponível: http://reflora.jbrj.gov. br/ reflora/herbarioVirtual/ConsultaPublicoHVUC /ConsultaPublicoHVUC.do. Acesso: 08 jun. 2020 .

Ribeiro-Silva, S., Medeiros, M.B., Gomes, B.M., Seixas, E.N.C., Silva, M.A.P., 2012. Angiosperms from the Araripe National Forest, Ceará, Brazil. Check List 8, 744-751.

Rodal, M.J.N., Sales, M.F., Silva, M.J., Silva, A.G., 2005. Flora de um brejo de altitude na escapa oriental do planalto da Borborema, PE, Brasil. Acta Botanica Brasilica 19, 843-858.

Sales, M.F., Mayo, S.J., Rodal, M.J.N., 1998. Plantas vasculares das florestas serranas de Pernambuco: um checklist da flora ameaçada dos brejos de altitude, Pernambuco - Brasil. Universidade Federal Rural de Pernambuco, Recife.

Santos, J.E.G., Benício, R.M.A., Silva, J.M., Brito, C.M., Ricarte, M.C.C., Figueiredo, C.U.L., 2020. Fortalecendo o ensino de ciências através da pesquisa paleontológica na bacia sedimentar do araripe, Ceará - Brasil. Brazilian Journal of Development 6, 2887228885.

Silveira, A.P., Loiola, M.I.B.; Gomes, V.S., LimaVerde, L.W. Oliveira, T.S., Silva, E.F., Otutumi, A.T., Ribeiro, K., Xavier, F.A.S., Bruno, M.M.A., Souza, S.S.G., Araújo, F.S., 2020. Flora de Batiruté - Ceará: A west island in the Brazilian semiarid. Flora e Ambiente 27, e20180320.

Silveira, A.P., Menezes, B.S., Loiola, M.I.B., Lima-Verde, L.W., Zanina, D.N., Carvalho, E.C.D., Souza, B.C., Costa, R.C., Mantovani, W., Menezes, M.O.T., Flores, L.M.A., Nogueira, F.C.B., Matias, L.Q., Barbosa, L.S., Gomes, F.M., Cordeiro, L.S., Sampaio, V.S., Batista, M.E.P., Soares Neto, R.L., Silva, M.A.P., Campos, N.B., Oliveira, A.A., Araújo, F.S., 2020. Flora and annual distribution of flowers and fruits in the Ubajara National Park, Ceará, Brazil. Flora e ambiente 27, e20190058.

Simões Neto, J.C., Alencar, R.T.F., Rocha, A.M., 2018. Identificação de pontos para a prática de Educação Ambiental na Região Metropolitana 
do Cariri Cearense. Cadernos de Cultura e Ciência 17, 41-62.

Santo, F.D.S., Figueiredo, M.F., 2018. Diversidade de plantas trepadeiras do Pico de Itacoatiara, Itapipoca, maciço de Uruburetama, Ceará, Brasil. Biota Amazônia 8, 4-7.

Tavares Filho, G.A., Oliveira, F.F., Mascarenhas, N.M.H., Araújo, C.A.S., Matias, S.S.R., Gregório, M.G., Oliveira, A.G., 2020. Qualidade do solo em áreas nativas e cultivadas na Chapada do Araripe no semiárido do nordeste brasileiro. Research, Society and Development 9, e8809108975.
Tofeti, R.A., Campos, N., 2019. Unidades de Conservação e o território no Brasil: estudos de caso em quatro biomas. Sociedade e Natureza 31, 1-23.

Thiers B [continuamente atualizado]. Index herbariorum: a global directory of public herbaria and associated staff. New York Botanical Garden's Virtual Herbarium. [Online]. Disponível: http://sweetgum. nybg. org/science/ih/. Acesso: 12 jun. 2020. 